\title{
Do Dynamic Linkages Exist Among European Carbon Markets?
}

Scott J. Niblock, Southern Cross University, Australia

Jennifer L. Harrison, Southern Cross University, Australia

\begin{abstract}
In this paper we examine statistical relationships among European carbon markets from 2005 to 2010. We use a time-series approach using 1,220 daily (spot and forward) price data observations from Phase I and Phase II of the European Union Emissions Trading Scheme (EU ETS). Procedures such as unit root, cointegration, vector error correction models (VECMs), Granger causality, and generalised impulse response functions are employed in the analysis. The results reveal dynamic linkages among spot and forward carbon prices in Phases I and II, indicating that joint price discovery is taking place in carbon markets (at least in the short-run). However, evidence of constrained long-run information flows in Phase II, as indicated by the joint shortand long-run Granger causality testing, may be problematic for policy makers. This finding suggests that the coordinated policies designed to improve the operation and transparency of the EU ETS in Phase II may have actually been counter-effective. If carbon pricing mechanisms are dysfunctional, this has implications for the informational efficiency of carbon markets in Phase II and beyond, thus signalling the possibility of arbitrage and other profitable trading opportunities for market participants. Further research could attempt to address these issues.
\end{abstract}

Keywords: Carbon Markets; EU ETS; Cointegration; Granger Causality; Impulse Response Functions

\section{INTRODUCTION}

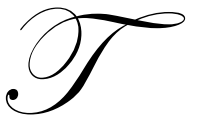

he theoretical appeal of carbon trading is compelling from an environmental perspective but what is the attraction of carbon from an investment perspective? The investment potential of carbon markets is substantial if carbon is deemed to be an alternative asset class. Carbon cannot be considered a "tangible" commodity because of its physical characteristics (e.g., there is no natural demand for carbon abatement as an asset) (Blair, 1998; World Bank, 2008). However, carbon is traded similarly to other tangible commodities (e.g., oil, gold, wheat, etc), with changes in value recognised by the forces of supply (i.e., allowance allocation caps) and demand (i.e., economic growth) for carbon allowances (Andrew, 2008; Blair, 1998; Kemfert et al. 2004). The possibility of linkages with other financial assets and commodities, together with market growth supporting liquidity, has highlighted the attractiveness of carbon as a global investment market (Abraham, 2007; Benz \& Hengelbrock, 2008). Moreover, with carbon market players being able to hedge, invest or speculate in allowances, the price behaviour and dynamics of carbon has become an issue of major importance in the financial arena (Miclăus et al. 2008).

Despite the perceived investment potential of carbon trading, the global politics involved are complex. A lack of binding international agreements and cooperation between member countries of the United Nations Framework Convention on Climate Change (UNFCCC), ongoing policy procrastination, increasing climate change scepticism, and heightened economic uncertainty due to the global financial crisis (GFC) all threaten to undermine the overall objective of the emerging market. Further, it is questionable how carbon as a "stand-alone" asset class will hold up against these political, environmental and economical constraints. The abundant risk associated with these constraints is indeed a concern for the price return characteristics of carbon markets. The operational efficiency of carbon markets has also been criticised on a range of issues including compliance and permit allocation standards, government intervention, market illiquidity, inadequate market regulation, poor emissions verification, price instability, lack of market transparency, and market manipulation (Egenhoffer, 2007; Taylor, 
2007; Willis \& Fitz-Gerald, 2007). It is possible that these alleged operational inefficiencies have restricted information flow within the market, stymied growth, and lead to the emergence of predictable price patterns. If this is the case, carbon pricing mechanisms may be sending incorrect signals to market participants, resulting in informational inefficiency, greater risk and/or market failure. So what are the implications for market participants if European spot and forward carbon markets are not dynamically linked? The uncertainty surrounding these statistical linkages therefore deserves greater academic scrutiny.

The efficient flow of information between spot and forward markets is fundamentally addressed by questioning whether forward and spot markets are dynamically linked. Fama (1991) suggests that a market is efficient if futures prices move conjointly with spot prices and if it offers an unbiased estimation of the future spot price. Hence, future prices are an unbiased predictor of the future spot price, implying that spot and futures prices share a long-run equilibrium relationship. A necessary condition for effective risk management is the existence of a long-run equilibrium relationship between spot and futures prices (Fama, 1991). If this relationship did not exist, the spot and futures prices would deviate by assuming independent stochastic paths, resulting in additional risk exposure. Thus, an inefficient futures market could undermine the efficiency of the underlying or "physical" market (Milunovich \& Joyeux, 2007). The relationship between spot and futures markets is upheld by arbitrageurs, such that a no-arbitrage pricing association between the futures price and the underlying spot price is established by the net cost of holding the asset relative to taking the futures position (Fedderke \& Joao, 2001). In endeavouring to exploit relative mispricing in spot and futures markets, arbitrageurs ensure that fair value is rapidly re-established (Milunovich \& Joyeux, 2007). Furthermore, this understanding of the impact of arbitrage leads to a specific conception of efficient spot and futures markets (Clements \& Hendry, 1995).

Dwyer \& Wallace (1992) indicate that this required absence of cointegration is based on the Fama (1991) conception of efficient markets, in which the prices of assets would fully reflect all available relevant information. As a consequence, it should not be possible to predict a price series in one of the futures or spot markets on the basis of the other, precluding the possibility of cointegration. Hence, the presence of any cointegrating relationship between futures and spot prices was held to contradict the Fama (1991) definition of efficiency because it would imply that one price series could help forecast the other. However, since the no-arbitrage definition of efficiency presumes that all profitable arbitrage opportunities have been exploited and reflected in spot and futures prices, it will be consistent with the presence of cointegration so long as the impact of transactions and opportunity costs are appropriately accounted for (Fedderke \& Joao, 2001). Therefore, futures prices and spot prices are linked by the arbitrage relationship, making cointegration possible. While earlier understanding of the relationship between cointegration and efficiency would have insisted on a verdict of inefficiency for such a market, this does not follow for the no-arbitrage definition of efficiency in spot and futures markets (Fedderke \& Joao, 2001).

A myriad of empirical work has been undertaken to challenge the efficient information transmission between spot and forward prices in financial markets, however, modest attention has been paid to emerging carbon markets, despite them being a major policy response to what is arguably considered one of the most important global challenges humankind has encountered. Several studies (Christiansen et al. 2005; Ellerman, 2005; Ellerman \& Buchner, 2008; Ellerman et al. 2003; McKibbin \& Wilcoxen, 2006; Seifert et al. 2008) have been published in the economics literature on the science, mechanisms and policy implications of carbon markets, although very little empirical research has been undertaken from a financial economic perspective. Alberola (2006), Benz \& Hengelbrock (2008), Boutaba (2009), Charles et al. (2010), Chevallier (2010), Milunovich \& Joyeux (2007), and Uhrig-Homburg \& Wagner (2009) have addressed these issues to some extent. The authors discover similar dynamic relationships in spot and forward European carbon markets, suggesting joint price discovery and a reasonable degree of informational efficiency (which could be attributed to the increased liquidity of carbon markets and expansion of organised trading). They also infer that carbon markets appear to be useful for investment, hedging and risk mitigation purposes, are unpredictable, and have been informationally efficient since the inauguration of the EU ETS. However, the validity of this research remains questionable given the time frames and methodologies employed.

Carbon markets clearly fit the description of an emerging investment market but it remains uncertain as to whether spot and forward prices are dynamically linked. Considering the relatively small and out-dated data samples and limited/fragmented methodologies in these studies, it is appropriate to re-assess dynamic linkages among 
European spot and forward carbon markets (particularly in light of growing climate change policy uncertainty and volatility displayed in financial markets due to the GFC). Therefore, the aim of this paper is to examine statistical relationships among European spot and forward carbon markets from 2005 to 2010. Procedures such as unit root (Dickey \& Fuller, 1981), cointegration (Johansen, 1991, 1995), vector error correction models (VECMs), Granger (1969) causality, and generalised impulse response functions (as utilised by Payne \& Sahu (2004)) are carried out in the analysis. The remainder of this paper is organised as follows: Sections 2 and 3 outline the data and methodology required to carry out the analysis. Empirical results are presented in Section 4. The paper is concluded in Section 5.

\section{DATA}

We employ 1,220 daily closing EU ETS Allowance price observations from 2005 to 2010. Observations are categorised as either spot (EUAS) or forward (EUAF-2007, EUAF-2008, EUAF-2009, EUAF-2010, EUAF-2011, and EUAF-2012) price series. The sample is divided into two sub-samples covering Phase I (25 April 2005 to 14 December 2007) and Phase II (25 February 2008 to 5 March 2010). The data are collected from various exchanges and historical price databases. EUAS data are obtained from "BlueNext" and EUAF data are collected from the "European Climate Exchange" (ECX). Log returns of the price series are calculated using the continuously compounded formula:

$$
R_{t}=\ln \left(\frac{P_{t}}{P_{t-1}}\right),
$$

where $P t$ is the price series at time $t, \ln$ is the natural logarithm, and $R t$ represents the log return series. Note that $R t$ $=\ln (P t)-\ln (P t-1)=\Delta \ln P t$. The statistical software used to analyse this data is EViews 7.2.

\section{METHODOLOGY}

\section{Unit root tests}

The augmented Dickey \& Fuller (ADF) (1981) test forms a parametric correction for higher-order correlation by assuming that the $y$ series follows an $\operatorname{AR}(\rho)$ process and including $\rho$ lagged difference terms of the dependent variable $y$ to the right-hand side of the test regression:

$$
\Delta y_{t}=\alpha y_{t-1}+x_{t}^{\prime} \delta+\beta_{1} \Delta y_{t-1}+\beta_{2} \Delta y_{t-2}+\ldots+\beta_{\rho} \Delta y_{t-\rho}+v_{t}
$$

Both the level series and differenced price series are considered. When the absolute level of the ADF $t$ ratios is greater than the critical value of -3.4164 , the null hypothesis is accepted at the 5\% significance level. Acceptance of the null hypothesis implies a non-stationary process; that is, a unit root exists in the price series, and the process is $I(1)$. Rejection of the null hypothesis asserts that a stationary process is evident; that is, a unit root is not present, and the price series are $I(0)$. If the tests on the log level price series fail to reject the null, then they are differenced once. If the null hypothesis still cannot be rejected, then the price series are differenced $d$ times until the unit root null is rejected. Once the null is rejected after first or $d$ times differencing in ADF testing, this confirms the $\log$ level price series contain a single unit root, that is, $I(1)$, and the investigation can proceed with cointegration testing (e.g., examining combinations of individual $I(1)$ price series to establish whether they are $I(0)$ or stationary).

\section{Cointegration tests}

Johansen $(1991,1995)$ cointegration allows estimation and testing of long-run equilibrium relations in the presence of short-run deviations from equilibrium. The trace statistic for the null hypothesis of $r$ cointegrating relations is computed as: 


$$
L R_{t r}(r \backslash k)=-T \sum_{i=r+1}^{k} \log \left(1-\lambda_{i}\right),
$$

The maximum eigenvalue statistic tests the null hypothesis of $r$ cointegrating relations against the alternative of $r+1$ cointegrating relations and is computed as:

$$
L R_{\max }(r \backslash r+1)=-T \log \left(1-\lambda_{r+1)}=L R_{t r}(r \backslash k)-L R_{t r}(r+1 \backslash k),\right.
$$

The Johansen procedure includes a constant (no trend) in the CE and test VAR for combinations of the price series but do not include a cost-of-carry term. Lag lengths are specified as pairs of intervals in first differenced terms and chosen by the Schwarz information criterion (SIC). The null hypothesis is accepted when the absolute values of the maximum eigenvalue and trace statistics are smaller than their respective critical values at the 5\% significance level. Maximum Eigenvalue critical values are 52.36, 46.23, 40.08, and 33.88 for ranks $0, \leq 1, \leq 2$, and $\leq 3$ respectively. Trace critical values are $159.53,125.62,95.75$, and 69.82 for ranks $0, \leq 1, \leq 2$, and $\leq 3$ respectively. Acceptance of the null at rank $r=0$ indicates that there are no CEs between the price series (that is, combined price series follow an $I(1)$ process). Rejection of the null hypothesis at rank $r \leq 1$ infers that there is at least one CE between the price series and evidence of stationarity (that is, the combined price series follow an $I(0)$ process). If this is the case, cointegrated price series can be utilised for investigation of short- and long-run Granger causing relationships via a vector error correction model (VECM) framework.

\section{Granger causality tests}

Testing Granger (1969) causality from " $\mathrm{X}$ " to "Y" and "Y" to "X" begins with a VECM estimation. A VECM is a restricted VAR designed for use with non-stationary series that are known to be cointegrated. The cointegration term is referred to as the error correction term (ECT) since the deviation from long-run equilibrium is corrected gradually through a series of partial short-run adjustments. Statistical tests on the individual equations can then be used to establish the direction of Granger causality between the pair-wise combinations of the series. For instance, a VECM for two cointegrated variables would take the following form:

$$
\begin{aligned}
& \Delta x_{t}=\beta_{1}+\sum_{i=1}^{m} \alpha_{1 i} \Delta x_{t-i}+\sum_{i=1}^{m} y_{1 i} \Delta y_{t-1}+\omega_{1} E C T_{t-1}+\mu_{1 t} \\
& \Delta y_{t}=\beta_{2}+\sum_{i=1}^{m} \alpha_{2 i} \Delta x_{t-i}+\sum_{i=1}^{m} y_{2 i} \Delta y_{t-1}+\omega_{2} E C T_{t-1}+\mu_{2 t},
\end{aligned}
$$

Short- and long-run Granger causality can be examined from the estimated VECM through two channels of causality. The first channel observes the significance of the lagged values of the differenced variables in the shortrun (and is referred to as short-run or "weak" Granger causality), and the second channel explores the ECT as a measure of long-run Granger causality. Notably, short- and long-run Granger causality can be tested using the $t$-test. The significance of the two channels of Granger causation can then be investigated using the joint short- and longrun (or "strong") Granger causality test, which identifies variables exposed to a short-run adjustment in order to reestablish long-run equilibrium, following a shock. The joint short- and long-run Granger causality test can be carried out by observing the following AR models of order $p$ and $q$ :

$$
Y_{t}=\sum_{i=1}^{p} \alpha_{i} Y_{t-i}+\sum_{j=1}^{q} \beta_{j} X_{t-j}+\mu_{t}
$$




$$
X_{t}=\sum_{i=1}^{p} \alpha_{i} X_{t-i}+\sum_{j=1}^{q} \beta_{j} Y_{t-j}+v_{t}
$$

where $\mu_{t}$ and $v_{t}$ are white noise, $p$ is the order of the lag $Y$, and $q$ is the order of the lag for $X$ (Stock \& Watson, 2003). The restricted models are therefore:

$$
\begin{aligned}
& Y_{t}=\sum_{i=1}^{p} \alpha_{i} Y_{t-i}+v_{t} \\
& X_{t}=\sum_{i=1}^{p} \alpha_{i} X_{t-i}+v_{t},
\end{aligned}
$$

with the standard Wald $F$-statistic providing a formal test for joint short- and long-run Granger causality:

$$
F=\frac{\left(S S R_{1}-S S R_{2}\right) / q}{S S R_{2} /(n-p-q)}
$$

A statistically significant $t$-statistic( $F$-statistic) indicates short-run or long-run(joint short- and long-run) unidirectional Granger causality from market " $\mathrm{X}$ " to market " $\mathrm{Y}$ ", or short-run or long-run(joint short- and long-run) unidirectional Granger causality from the interchanged market " $Y$ " to market " $X$ ". If both series of " $X$ " and " $Y$ " $t$ statistics( $F$-statistics) are statistically significant, then a short-run or long-run(joint short- and long-run) feedback or bidirectional Granger causal relationship exists. Moreover, if the $t$-statistics $(F$-statistics) are statistically insignificant in both regressions, then short-run or long-run(joint short- and long-run) Granger causal independence is evident (Stock \& Watson, 2003). Hypothesis testing is performed on each pair-wise combination of the price series and the tests include a constant (no trend) in the CE and test VAR. The SIC is used for both the VECM first differenced lag order interval specification and $p$ and $q$ lag selections. No restrictions are applied to the VECMs. When the absolute levels of the $t$-statistic (short- and long-run) and $F$-statistic (joint short- and long-run) are less than the critical values of \pm 1.96 and 3.85 respectively, the null hypothesis is accepted at the $5 \%$ significance level. Acceptance of the null indicates that price series "X" ("Y") does not Granger-cause price series " $Y$ " ("X"). Rejection of the null asserts that price series " $\mathrm{X}$ " ("Y") Granger-causes price series " $Y$ " ("X"). Once Granger causality testing is finalised, impulse response functions can be employed to confirm the Granger causality findings and determine whether unexpected changes in one market can have a significant effect on another, as per the following discussion.

\section{Generalised impulse response functions}

The parameter estimates of the VECM indicate how returns respond to expected changes in the returns from other markets (through Granger causality testing). On the other hand, a shock to the $i$-th variable not only affects the $i$-th variable but is also transmitted to all of the other endogenous variables through the lag structure of the VECM. An impulse response function therefore traces the effect of a one-time (or unanticipated) shock to one of the innovations on current and future values of the endogenous variables. Innovations may be viewed as having a common component which cannot be associated with a specific variable (Payne \& Sahu, 2004). The generalised impulse response function for a one standard deviation shock to the $i$-th equation in the VECM on the $j$-th variable at horizon $n$ is defined by:

$$
G_{i j, n}=\left(e_{j} A_{n} \sum e_{i}\right) / \sigma_{i i}^{1 / 2}, \quad i, j=1,2, \ldots, m
$$




\section{RESULTS}

\section{Summary statistics}

Exhibit 1 indicates that Phase I and II were volatile trading periods.

Exhibit 1: Summary statistics

\begin{tabular}{|c|c|c|c|c|}
\hline Phase I & $E U A S$ & $E U A F-07$ & $E U A F-08$ & EUAF-09 \\
\hline Observations & 690 & 690 & 690 & 690 \\
\hline Min. Return & $-51.08 \%$ & $-138.63 \%$ & $-28.82 \%$ & $-28.11 \%$ \\
\hline Max. Return & $51.08 \%$ & $109.86 \%$ & $18.65 \%$ & $19.32 \%$ \\
\hline Mean & -0.0092 & -0.0092 & 0.0004 & 0.0004 \\
\hline Annualised Return & $-229.49 \%$ & $-229.59 \%$ & $10.40 \%$ & $11.11 \%$ \\
\hline Standard Deviation & $7.38 \%$ & $9.71 \%$ & $3.00 \%$ & $2.97 \%$ \\
\hline Skewness & -0.4245 & -2.0695 & -1.4789 & -1.3987 \\
\hline Kurtosis & 13.4939 & 87.6807 & 19.6928 & 19.3825 \\
\hline Jarque-Bera (JB) & $3186.71 *$ & $206,653.80 *$ & $8,262.69^{*}$ & $7,941.11 *$ \\
\hline Phase II & $E U A S$ & $E U A F-10$ & $E U A F-11$ & $E U A F-12$ \\
\hline Observations & 530 & 530 & 530 & 530 \\
\hline Min. Return & $-10.29 \%$ & $-9.30 \%$ & $-9.06 \%$ & $-9.33 \%$ \\
\hline Max. Return & $10.55 \%$ & $11.35 \%$ & $11.53 \%$ & $11.75 \%$ \\
\hline Mean & -0.0008 & -0.0010 & -0.0001 & -0.0001 \\
\hline Annualised Return & $-19.85 \%$ & $-25.03 \%$ & $-24.73 \%$ & $-24.40 \%$ \\
\hline Standard Deviation & $2.66 \%$ & $2.64 \%$ & $2.63 \%$ & $2.54 \%$ \\
\hline Skewness & -0.2269 & -0.0608 & -0.0556 & -0.0786 \\
\hline Kurtosis & 4.6026 & 4.9013 & 4.9422 & 5.1516 \\
\hline Jarque-Bera (JB) & $61.26^{*}$ & $80.16^{*}$ & $83.57 *$ & $102.78 *$ \\
\hline
\end{tabular}

Notes: * denotes statistical significance at $5 \%$ level.

\section{Unit root tests}

Exhibit 2 below reports the results for the unit root tests conducted. ADF null hypotheses are accepted/rejected at the 5\% level for all log level/differenced price series across both Phases. The findings imply that the log level price series are $I(1)$ and contain a unit root. Following acceptance that the log level price series are integrated of the same order $I(1)$, an examination of cointegration is possible.

Exhibit 2: Unit root tests

\begin{tabular}{lcc}
\hline Phase I & & $A D F \Delta \ln \left(P_{t}\right)$ \\
\hline Series & $A D F \ln \left(P_{t}\right)$ & $-28.2104^{*}$ \\
\hline$E U A S$ & -1.3948 & $-30.7354^{*}$ \\
$E U A F-07$ & -1.4033 & $-22.9054^{*}$ \\
$E U A F-08$ & -2.7642 & $-23.3094^{*}$ \\
\hline$U U F-09$ & -2.7834 & \\
\hline & & $A D F \Delta \ln \left(P_{t}\right)$ \\
\hline Phase II & & $-17.6231^{*}$ \\
\hline$E U A S$ & $A D F \ln \left(P_{t}\right)$ & $-17.3213^{*}$ \\
$E U A F-10$ & -1.4683 & $-17.3944^{*}$ \\
EUAF-11 -12 & -1.5457 & $-17.1305^{*}$ \\
\hline
\end{tabular}

Notes: $\ln \left(P_{t}\right)=$ Log level. $\Delta \ln \left(P_{t}\right)=$ Log first difference. ADF critical values are taken from MacKinnon (1996). * denotes statistical significance at $5 \%$ level. ADF lag lengths chosen by SIC. Tests include a constant and trend. 


\section{Cointegration tests}

Multivariate Johansen test results are presented in Exhibit 3. The null hypothesis is rejected in Phases I and II, with statistically significant maximum eigenvalue and trace statistics confirming the existence of three (3) cointegrating relationships among all the carbon price series at the 5\% level. The results establish that cointegration is occurring between the prices series. Accepting the evidence presented in the Johansen tests, it is possible that Granger causality may be flowing between pair-wise combinations of the price series.

Exhibit 3: Johansen Cointegration tests

\begin{tabular}{|c|c|c|c|c|c|}
\hline Equation & Rank & $r$ & Eigen value & Max. Eigen value statistic & Trace test statistic \\
\hline \multirow[t]{4}{*}{ Phase I } & 0 & & 0.2235 & $174.0167 *$ & $332.7717 *$ \\
\hline & $\leq 1$ & & 0.0849 & $61.0508 *$ & $158.7550 *$ \\
\hline & $\leq 2$ & & 0.0531 & 37.5692 & $97.7042 *$ \\
\hline & $\leq 3$ & & 0.0297 & 20.7619 & 60.1350 \\
\hline Equation & Rank & $r$ & Eigen value & Max. Eigen value statistic & Trace test statistic \\
\hline \multirow[t]{4}{*}{ Phase II } & 0 & & 0.2121 & $125.8517^{*}$ & $299.6558 *$ \\
\hline & $\leq 1$ & & 0.1166 & $65.4718 *$ & $173.8041 *$ \\
\hline & $\leq 2$ & & 0.0753 & $41.3612 *$ & $108.3323 *$ \\
\hline & $\leq 3$ & & 0.0483 & 26.1169 & 66.9712 \\
\hline
\end{tabular}

Notes: Rank $r$ is the number of CEs according to each tested hypothesis. Lag length chosen by SIC. Critical values taken from MacKinnon et al. (1999). * denotes significance at the 5\% level.

\section{Granger causality tests}

Exhibit 4 below shows Phase I VECM test results. In the short-run, the null hypothesis is rejected at the 5\% level for pair-wise combinations of EUAF-08-EUAS and EUAS-EUAF-07. Remaining combinations accept the null.

\begin{tabular}{lccccccc}
\multicolumn{7}{c}{ Exhibit 4: VECM (Phase I) } \\
\hline Series & $\Delta E U A S$ & $\Delta E U A F-07$ & $\Delta E U A F-08$ & $\Delta E U A F-09$ & $E C T_{(C E I)}$ & $E C T_{(C E 2)}$ & $E C T_{(C E 3)}$ \\
\hline$\Delta E U A S$ & - & 0.0271 & $1.6954^{*}$ & -1.2870 & $-0.2178^{*}$ & $0.2011^{*}$ & $-1.2056^{*}$ \\
& & {$[0.7822]$} & {$[2.1484]$} & {$[-1.6198]$} & {$[-5.7156]$} & {$[5.3116]$} & {$[-2.6173]$} \\
$\Delta E U A F-07$ & $0.2362^{*}$ & - & 1.6279 & -1.4356 & $0.4046^{*}$ & $-0.4163^{*}$ & -0.9715 \\
& {$[4.4190]$} & & {$[1.6757]$} & {$[-1.4677]$} & {$[8.6263]$} & {$[-8.9315]$} & {$[-1.7133]$} \\
$\Delta E U A F-08$ & 0.0304 & -0.0003 & - & -0.2107 & -0.0043 & 0.0063 & 0.1385 \\
& {$[1.6255]$} & {$[-0.0188]$} & & {$[-0.6158]$} & {$[-0.2634]$} & {$[0.3844]$} & {$[0.6983]$} \\
$\Delta E U A F-09$ & 0.0292 & 0.0007 & 0.6294 & - & -0.0031 & 0.0060 & 0.2487 \\
& {$[1.5824]$} & {$[0.0478]$} & {$[1.8763]$} & & {$[-0.1941]$} & {$[0.3752]$} & {$[1.2701]$} \\
\hline
\end{tabular}

Notes: $\Delta$ is the difference operator. $E C T$ is the error correction term. $C E$ is the cointegrating equation. Numbers without brackets indicate coefficients. Numbers in brackets indicate $t$-statistics. * denotes statistical significance at $5 \%$ level. Lag lengths are selected by SIC. Columns $=$ independent variables. Rows $=$ dependent variables.

This suggests that there is unidirectional Granger causality running from the 2008 forward price to the spot price and from the spot price to the 2007 forward price. In the long-run, the null hypothesis is rejected at the 5\% level for combinations of $E U A S$ and $E U A F-07$. The null is accepted for other combinations. Statistically significant ECTs suggest that spot and 2007 forward carbon prices return to a long-run equilibrium whenever there are deviations from the cointegrating relationship. Also, price transmission efficiency took place between spot and 2007 forward carbon prices but not with 2008 and 2009 forward carbon prices.

Exhibit 5 shows Phase I Granger causality test results. Joint short- and long-run statistical significance is found (with rejection of the null hypothesis at the 5\% level) between pair-wise combinations of EUAF-07-EUAS, EUAS-EUAF-07, and EUAF-08-EUAF-09. The null is accepted for other combinations. This implies that there is bidirectional Granger causality running between the spot and 2007 forward prices, and unidirectional Granger 
causality flowing from the 2008 forward price to the 2009 forward price. Notably, spot and 2007 forward prices fail to demonstrate at least unidirectional Granger causality with 2008 and 2009 forward prices.

Exhibit 5: Granger Causality Tests (Phase I)

\begin{tabular}{|c|c|c|c|c|}
\hline Series & $E C T \& \triangle E U A S$ & $E C T \& \triangle E U A F-07$ & $E C T \& \triangle E U A F-08$ & $E C T \& \triangle E U A F-09$ \\
\hline$\triangle E U A S$ & - & $58.2933^{*}$ & 0.3348 & 0.2395 \\
\hline$\triangle E U A F-07$ & $176.5370^{*}$ & - & 0.0076 & 0.0002 \\
\hline$\triangle E U A F-08$ & 0.2696 & 0.2844 & - & 2.8142 \\
\hline$\triangle E U A F-09$ & 0.2698 & 0.2834 & $4.2007 *$ & - \\
\hline
\end{tabular}

Notes: $\Delta$ is the difference operator. ECT is the error correction term. * denotes statistical significance at 5\% level. Lag lengths are selected by SIC. Columns = independent variables. Rows $=$ dependent variables.

Exhibit 6 below illustrates Phase II VECM findings. In the short-run, the null hypothesis is rejected at the 5\% level for pair-wise combinations of EUAS-EUAF-10, EUAS-EUAF-11, EUAF-10-EUAF-11, EUAS-EUAF-12, and EUAF-10-EUAF-12. Remaining combinations accept the null. This suggests that there is unidirectional Granger causality running from the spot price to forward (2010-12) prices and the 2010 forward price to the other forward (2011-12) prices. In the long-run, the null hypothesis is rejected at the 5\% level for combinations of EUAS, EUAF-11, and EUAF-12. The null is accepted for other combinations. Statistically significant ECTs suggest that spot and 201112 forward carbon prices return to a long-run equilibrium whenever there are deviations from the cointegrating relationship. Also, price transmission took place between spot and 2011-2012 forward carbon prices but not with the 2010 forward carbon price.

Exhibit 6: VECM (Phase II)

\begin{tabular}{|c|c|c|c|c|c|c|c|}
\hline Series & $\Delta E U A S$ & $\Delta E U A F-10$ & $\Delta E U A F-11$ & $\Delta E U A F-12$ & $\mathrm{ECT}_{(C E I)}$ & $\mathrm{ECT}_{(C E 2)}$ & $\mathrm{ECT}_{(C E 3)}$ \\
\hline$\Delta E U A S$ & - & -0.7231 & 0.3161 & 0.5357 & $-0.2236^{*}$ & $0.8177^{*}$ & $-0.8699^{*}$ \\
\hline & & {$[-1.5056]$} & {$[0.9383]$} & {$[1.2222]$} & {$[-2.9890]$} & {$[2.9469]$} & {$[-2.2217]$} \\
\hline$\Delta E U A F-10$ & $0.4133^{*}$ & - & 0.2087 & 0.6628 & -0.1426 & 0.5330 & -0.5711 \\
\hline & {$[2.5617]$} & & {$[0.6231]$} & {$[1.5206]$} & {$[-1.9177]$} & {$[1.9317]$} & {$[-1.4667]$} \\
\hline$\Delta E U A F-11$ & $0.4543^{*}$ & $-1.0280^{*}$ & - & 0.7803 & $-0.1680^{*}$ & $0.8024^{*}$ & $-1.0523^{*}$ \\
\hline & {$[2.8545]$} & {$[-2.1823]$} & & {$[1.8149]$} & {$[-2.2896]$} & {$[2.9479]$} & {$[-2.7399]$} \\
\hline$\triangle E U A F-12$ & $0.3548^{*}$ & $-1.0196^{*}$ & 0.2070 & - & $-0.1406^{*}$ & 0.5008 & -0.5152 \\
\hline & {$[2.2845]$} & {$[-2.2180]$} & {$[0.6421]$} & & {$[-1.9633]$} & {$[1.8854]$} & {$[-1.3746]$} \\
\hline
\end{tabular}

Notes: $\Delta$ is the difference operator. $E C T$ is the error correction term. $C E$ is the cointegrating equation. Numbers without brackets indicate coefficients. Numbers in brackets indicate $t$-statistics. * denotes statistical significance at $5 \%$ level. Lag lengths are determined by SIC. Columns = independent variables. Rows $=$ dependent variables.

Exhibit 7 illustrates Phase II Granger causality findings. Joint short- and long-run statistical significance is found (with rejection of the null hypothesis at the 5\% level) between the pair-wise combination of EUAF-12-EUAF11. The null is accepted with other combinations. This implies there is unidirectional Granger causality flowing from the 2012 forward price to the 2011 forward price. Notably, other combinations of the spot and forward carbon prices fail to demonstrate unidirectional Granger causality. There is no evidence of bidirectional Granger causality in these markets. In order to substantiate the discovery of Granger-causing relationships in Phases I and II, impulse response functions are employed.

Exhibit 7: Granger Causality Tests (Phase II)

\begin{tabular}{|l|c|c|c|c|}
\hline \multicolumn{1}{|c|}{ Series } & $E C T \& \triangle E U A S$ & $E C T \& \Delta E U A F-10$ & $E C T \& \Delta E U A F-11$ & $E C T \& \triangle E U A F-12$ \\
\hline$\triangle E U A S$ & - & 0.9749 & 1.092 & 1.7268 \\
\hline$\triangle E U A F-10$ & 0.0023 & - & 1.2673 & 2.5243 \\
\hline$\triangle E U A F-11$ & 0.0004 & 0.0006 & - & $5.6539^{*}$ \\
\hline$\triangle E U A F-12$ & 0.4978 & 1.9565 & 1.9986 & - \\
\hline
\end{tabular}

Notes: $\Delta$ is the difference operator. ECT is the error correction term. * denotes statistical significance at 5\% level. Lag lengths are determined by SIC. Columns $=$ independent variables. Rows $=$ dependent variables. 


\section{Generalised impulse response functions}

Figures 1 and 2 illustrate the results of these response functions over a rolling 20-day trading horizon in Phase I and II respectively.

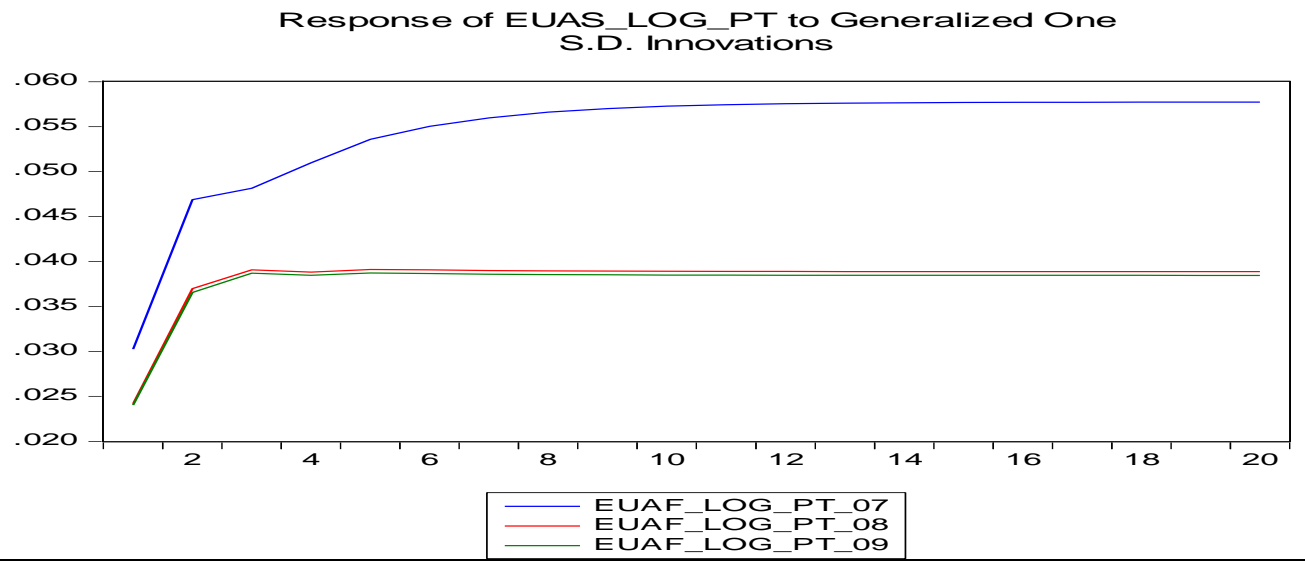

Figure 1: Impulse Response Functions (Phase I)

Figure 1 above illustrates that Phase I responses are instant and positive, however, there are discrepancies between the spot and forward carbon market responses (e.g., the spot price responds at a greater magnitude to the 2007 forward carbon price series compared to the 2008 and 2009 forward carbon price series, suggesting that Phase I carbon markets are segmented). Nevertheless, the spot price response to forward prices accurately reflects the respective standard deviation shocks.

Figure 2 shows that Phase II responses are fairly similar across the spot and forward carbon markets (albeit at lower response rates than Phase I). The spot price responses to the forward price shocks accurately reflect the respective standard deviations. Again, the responses are instant and positive. Responses increase sharply and then tail-off after approximately three days, indicating that information transmission between spot and forward prices is occurring, and at a faster rate than Phase I.

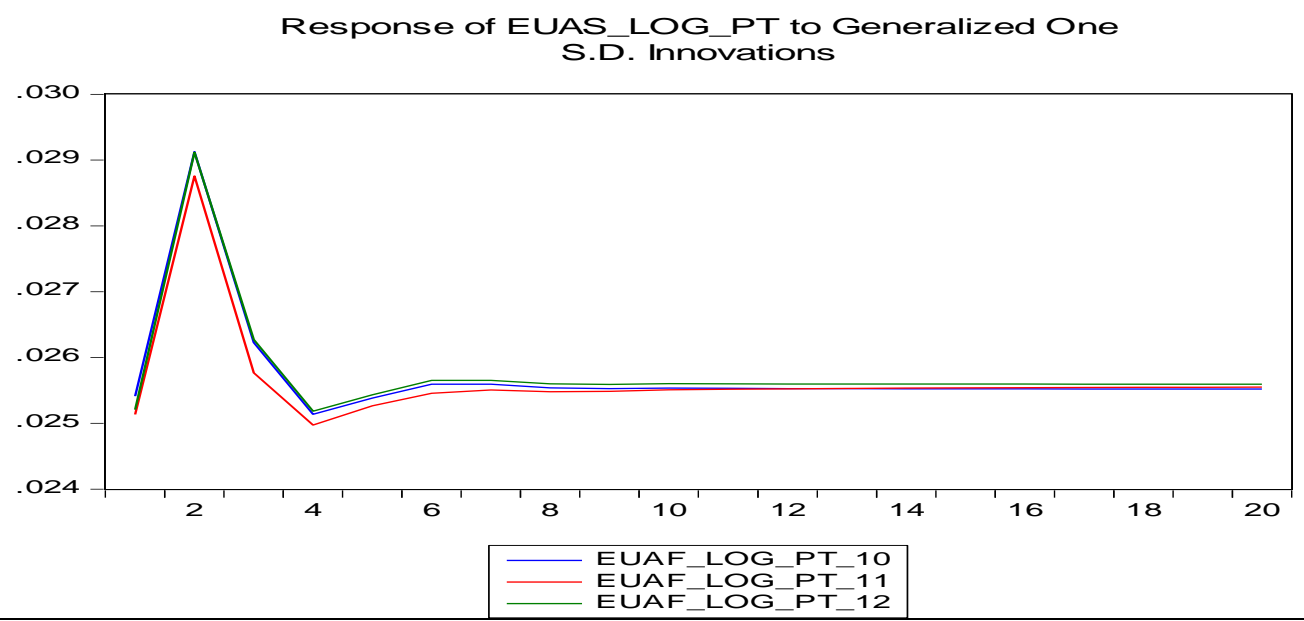

Figure 2: Impulse Response Functions (Phase II) 


\section{CONCLUSION}

This paper explores statistical linkages among European carbon markets from 2005 to 2010. Unit root and cointegration test results allow Granger causality testing. Granger causality test results reveal that dynamic linkages are flowing among spot and forward carbon markets in the short- and long-run and that information transmission is occurring in both Phases. However, the joint short- and long-run transmission of information in carbon markets remains questionable, particularly in Phase II. While carbon markets transmitted long-run information efficiently during Phase I, these linkages became inherently weaker in Phase II. Generalised impulse response functions confirm positive responses, suggesting spot prices react to unanticipated changes (or "shocks") from the broader carbon market immediately, and by similar magnitudes. The functions show that spot and forward carbon markets are interdependent and became more functional in Phase II (which is in contrast to the joint short- and long-run Granger causality findings).

Overall, the evidence presented is mixed. Dynamic linkages are evident in spot and forward European carbon markets, and joint price discovery and risk mitigation appears to be taking place (at least in the short-run). However, evidence of constrained long-run information flows in Phase II, as indicated by the joint short- and longrun Granger causality testing, may be problematic for policy makers. This finding suggests that the coordinated policies designed to improve the operation and transparency of the EU ETS may have actually been countereffective. It seems that the ongoing lack of global policy direction regarding climate change (as typified by the 2009 UNFCCC Copenhagen failure) and events such as the GFC may have had a material impact on efficient price transmission in European carbon markets. If carbon pricing mechanisms are dysfunctional, this has implications for weak-form carbon market efficiency in Phase II and beyond, thus signalling the possibility of arbitrage and other profitable trading opportunities for market participants. Further research could attempt to address these issues by employing univariate random walk tests and trading profitability rules.

\section{ACKNOWLEDGEMENTS}

The authors wish to acknowledge support received from Professor Michael Evans, Kaplan Australia, and Associate Professor Keith Sloan, Southern Cross Business School. We would also like to thank participants of the 2009 AFAANZ Doctoral Colloquium in Adelaide (particularly Associate Professor Robert Durand, University of Western Australia).

\section{AUTHOR INFORMATION}

Scott J. Niblock is a lecturer of finance at the Southern Cross Business School (SCBS), Gold Coast, Australia. He has been involved in undergraduate and postgraduate programs with SCBS for over four years, and teaches units such as security analysis and portfolio management, international finance, and business/corporate finance. Scott is also the SCBS Honours Coordinator. Scott is passionate about his research and is particularly interested in the financial economics of emerging carbon markets and the risk-adjusted return performance of socially responsible investments. He has also worked as a private client advisor in the stockbroking industry, gaining high level Australian stock and derivatives accreditation. E-mail: scott.niblock@scu.edu.au. Corresponding author

Dr Jennifer L. Harrison is Department Head Accounting Finance and Quantitative Methods and Southern Cross Business School Director of Research Training at Southern Cross University's Gold Coast Campus in Australia. Jennifer has taught in the areas of accounting, finance, economics and research methods in undergraduate and postgraduate programs for over 10 years. She has been actively involved in consulting projects across a variety of industries including banking, agriculture, software development and sport and fitness and for organizations such as Microsoft. Her research interests include strategic entrepreneurship, particularly within ICT firms, and impression management in the financial disclosures of listed companies. E-mail: jennifer.harrison@scu.edu.au 


\section{REFERENCES}

1. Abraham, A., 2007, Is carbon the new asset class? Infinance 121, 37-39.

2. Alberola, E., 2006, The informational efficiency of the EU ETS: An empirical evaluation on the spot and futures prices, Working Paper (University of Paris, France).

3. Andrew, B., 2008, Market failure, government failure and externalities in climate change mitigation: The case for a carbon tax, Public Administration and Development 28(5), 393-401.

4. Benz, E.A., and J. Hengelbrock, 2008, Liquidity and price discovery in the European $\mathrm{CO}_{2}$ futures market: An intraday analysis. Paper presented at the $21^{\text {st }}$ Australasian Finance and Banking Conference; 16-18 December, The University of New South Wales, Sydney, Australia.

5. $\quad$ Blair, R., 1998, Trading in carbon rights - legal issues, Australian Forest Grower May, 14-15.

6. Boutaba, M.A., 2009, Dynamic linkages among European carbon markets, Economics Bulletin, 29(2), 499511.

7. Charles. A., O. Darné, and J. Fouilloux, 2010, Testing the Martingale Difference Hypothesis in the EU ETS Markets for the $\mathrm{CO}_{2}$ Emission Allowances: Evidence from Phase I and Phase II, Working Paper. [Online; cited 14 July 2010]. Available: http://ideas.repec.org/p/hal/wpaper/hal-00473727_v1.html\#provider.

8. Chevallier, J., 2010, A note on cointegrating and vector autoregressive relationships between $\mathrm{CO}_{2}$ allowances spot and futures prices, Economics Bulletin 30(2), 1564-1584.

9. Christiansen, A.C., A. Arvanitakis, K. Tangen, and H. Hasselknippe, 2005, Price determinants in the EU emissions trading scheme, Climate Policy 5(1), 15-30.

10. Clements, M.P., and D.F. Hendry, 1995, Forecasting in cointegrated systems, Journal of Applied Econometrics 10(2), 127-146.

11. Dickey, D.A., and W.A. Fuller, 1981, Likelihood ratio statistics for autoregressive time series with a unit root, Econometrica 49(4), 1057-1072.

12. Dwyer, G.P. Jr, and M.S. Wallace, 1992, Cointegration and market efficiency, Journal of International Money and Finance 11(4), 318-327.

13. Egenhoffer, C., 2007, The making of the EU ETS: Status, prospects and implications for business, European Management Journal 25(6), 453-463.

14. Ellerman, D.A., 2005, A note on tradable permits, Environmental and Resource Economics 31(2), 123-131.

15. Ellerman, D.A., and B.K. Buchner, 2008, Over-allocation or abatement? A preliminary analysis of the EU ETS based on the 2005-06 emissions data, Environmental and Resource Economics 41(2), 267-287.

16. Ellerman, D.A., P.L. Joskow, D. Harrison Jr, 2003, Emissions trading in the U.S: Experience, lessons, and considerations for greenhouse gases (Pew Centre on Global Climate Change, Washington DC, U.S.).

17. Fama, E. F., 1991, Efficient capital markets: II, Journal of Finance 46(5), 1575-1617.

18. Fedderke, J., and M. Joao, 2001, Arbitrage, cointegration and efficiency in financial markets in the presence of financial crises, South African Journal of Economics 69(3), 366-384.

19. Granger, C.W.J., 1969, Investigating causal relations by econometric models and cross-spectral methods, Econometrica 37(3), 424-438.

20. Johansen, S., 1991, Estimation and hypothesis testing of cointegration vectors in Gaussian vector autoregressive models, Econometrica 59(6), 1551-1580.

21. Johansen, S., 1995, Identifying restrictions of linear equations with applications to simultaneous equations and cointegration, Journal of Econometrics 69(1), 111-132.

22. Kemfert, C., J. Diekmann, and H.J. Ziesling, 2004, Emissions trading in Europe: Effective tool or flight of fancy? Intereconomics 39(3), 119-121.

23. MacKinnon, J.G., 1996, Numerical distribution functions for unit root and cointegration tests, Journal of Applied Econometrics 11(6), 601-618.

24. MacKinnon, J.G., A.A. Haug, and L. Michelis, 1999, Numerical distribution functions of likelihood ratio tests for cointegration, Journal of Applied Econometrics 14(5), 563-577.

25. McKibbin, W.J., and P.J. Wilcoxen, 2006, A credible foundation for long term international cooperation on climate change, Discussion Paper (Brookings Discussion Paper in International Economics, Washington DC, U.S.).

26. Miclăus, P.G., R. Lupu, S.A. Dumitrescu, and A. Bobircă, 2008, Testing the efficiency of the European carbon futures market using event-study methodology, International Journal of Energy and Environment 2(2), 121-128. 
27. Milunovich, G. and R. Joyeux, 2007, Market efficiency and price discovery in the EU carbon futures market, Discussion Paper (Division of Economic and Financial Studies, Macquarie University, Australia).

28. Payne, J.E., and A.P. Sahu, 2004, Random walks, cointegration, and the transmission of shocks across global real estate and equity markets, Journal of Economics and Finance 28(2), 198-210.

29. Seifert, J., M. Uhrig-Homburg, and M.W. Wagner, 2008, Dynamic behaviour of $\mathrm{CO}_{2}$ spot prices, Journal of Environmental Economics and Management 56(2), 180-194.

30. Stock, J.H., and M.W. Watson, 2003, Introduction to Econometrics, International edn (Pearson Education Inc, Boston, Massachusetts, U.S.).

31. Taylor, R., 2007, Catching up with the new carbon cycle, ECOS 138, 12-15.

32. Uhrig-Homburg, M., and M.W. Wagner, 2009, Futures price dynamics of $\mathrm{CO}_{2}$ emission certificates - An empirical analysis, Journal of Derivatives 17(2), 73-88.

33. Willis, M., and L. Fitz-Gerald, 2007, Carbon Credits: The New Currency. [Online; cited 21 April 2008]. Available: http://www.wme.com.au/categories/emissions/feb5 07.php.

34. World Bank, 2008, State and Trends of the Carbon Market (World Bank Institute, Washington DC, U.S.). 